\title{
A descriptive study of sleep disorders and their impact in 2 selected schools in a divisional city of Bangladesh
}

\author{
C H Rasul ${ }^{1}$, K G Mostafa ${ }^{2}$, N N Baruri' ${ }^{2}$ M M Rahman ${ }^{3}$
}

Sri Lanka Journal of Child Health, 2014; 43(4): 212-218

\begin{abstract}
Background: Sleep disorders are common in children and adolescents and have an important negative impact on their quality of life.

Objective: This study was done to estimate the prevalence of sleep problems in 2 selected schools in a divisional city of Bangladesh and to evaluate the impact of sleep disorders on school performance.
\end{abstract}

Method: One thousand school children between 5 to 16 years of age from the two largest schools (one boys' and one girls' school) were randomly selected for this study from July to December 2011. A two step procedure involved self-administered questionnaire and direct interview of the affected children and parents. The questionnaire was based on diagnostic criteria for category based classification by American Academy of Sleep Medicine. Academic performance was evaluated on the basis of cumulative results of term examinations throughout the year.

Results: A total of $713(71.3 \%)$ questionnaires were eventually returned. Of the children, 353 were boys and 360 were girls. Three hundred and ninety two sleep problems were noted in 202 (28.3\%) school children and mean (SD) age of sufferer was 139 (32) months. Among the primary sleep problems, parasomnia $(47.8 \%)$ was highest followed by dyssomnia $(9.5 \%)$. Prominent disorders under parasomnia were nightmares $(7.4 \%)$, nocturnal enuresis $(4.1 \%)$ and sleep terror $(3.4 \%)$ and that under dyssomnia was obstructive sleep apnoea $(3.6 \%)$. School performance was significantly poor in the children with sleep disorders $(p<0.001)$. Parasomnias were much higher in girls than boys $(\mathrm{p}<0.001)$. Only 20 $(10.8 \%)$ parents consulted a physician for primary disorder.

${ }^{1}$ Professor, ${ }^{2}$ Assistant Professor, ${ }^{3}$ Assistant
Registrar, Department of Paediatrics, Khulna
Medical College \& Hospital, Khulna, Bangladesh

(Received on 5 March 2014: Accepted after revision on 25 April 2014)
Conclusions: In the 2 selected schools in Khulna city of Bangladesh $28.3 \%$ had sleep problems. Sleep disorders had a significant negative impact on school performance.

(Key words: Sleep disorder; schoolchildren; prevalence; school performance)

\section{Introduction}

Sleep quality among children is directly related to physical health, development of intelligence and emotional growth ${ }^{1,2}$. Sleep-wake disorders are common and have an impact on the quality of life of children but if they are promptly recognized and treated, the outcome is favourable ${ }^{3}$. Insufficient quantity and poor quality of sleep in children and adolescents result in excessive daytime sleepiness which often manifests as mood disturbances, hyperactivity, poor impulse control and neurocognitive dysfunction ${ }^{4,5}$. Lack of community awareness of the negative effect of sleep problems also contributes to under reporting of parents at medical consultation ${ }^{6-8}$.

Studies of children and adolescents in the general population have indicated that $20-30 \%$ have sleep problems of concern to parents ${ }^{4}$. Three general categories of sleep disorder are: initiating and maintaining sleep (dyssomnia), sleep-wake transition disorder (parasomnia) and arousal disorders $^{9-11}$. Mindell and Adair emphasized two major groups: dyssomnias and parasomnias ${ }^{12,13}$. American Academy of Sleep Medicine (AASM) has described over 80 problems in the International Classification of Sleep Disorders ${ }^{14}$. This widely accepted classification has two principal groups: primary disorders related entirely to sleep and secondary disorders related to other physical conditions.

Most of the available reports on sleep disorders are mainly focused on preschool children and are reported to be higher in young children and males ${ }^{15}$. However, sleep disorders in school children have rarely been evaluated and might be different from those in preschool children in magnitude, nature and aetiology ${ }^{16}$. 


\section{Objectives}

- To estimate the prevalence of sleep disorders in 2 selected schools in a divisional city of Bangladesh.

- To evaluate the impact of sleep disorders on school performance.

\section{Method}

Sleep disorders were studied in 2 selected schools in Khulna, a divisional city of Bangladesh. There are 18 secondary schools in Khulna city housing around 25,000 children between 5 to 16 years of age. The two biggest schools in Khulna are Coronation Girls' School and Khulna Zilla Boys' School which accommodate around 3000 students each in double shift. The schools were purposely selected in order to get a large number of students belonging to a wide range of socio-economic conditions. We assumed expected prevalence of sleep disorders in school children to be around $30 \%$. Using a precision level of $\pm 5 \%$ and confidence level of $95 \%$, a sample size of 400 in each school cluster was estimated. Keeping a non response rate of $25 \%$, a total sample of 500 students per school was finally estimated. Permission was taken from both heads of the institutes to carry out the study from July to December 2011

Most large scale surveys on child health problems are based on parental perception ${ }^{16}$. This cross sectional observational study was done in two steps as per design of Guilleminault and colleagues: selfadministered questionnaire and direct interview of the affected children and parents to minimize the weakness of recall bias and diagnostic confusion ${ }^{17}$. Students from each class were randomly selected for enrolment as study cases. Parents of the selected students and the school teachers were invited to a meeting to explain the purpose of the study. Questionnaires were handed over to the parents and guidelines were given on how to fill up the questionnaire along with the characteristics of 20 different sleep problems as included in the format. Children who did not return the questionnaire within two weeks were sent a reminder through the class teacher to maximize the response. In the second step, parents of children having sleep problems were invited to the Sleep Clinic in our hospital for a clinical interview. Elaborate history was reviewed and physical examination of the student was performed by the researchers to crosscheck the information in the questionnaire. A few mothers who failed to attend the clinic were interviewed over the telephone. The diagnosis of the sleep disorders under six categories was based on the criteria set by
$\mathrm{AASM}^{14}$. A problem being potentially dangerous to life or causing severe disruption to normal activities was considered as a major disorder ${ }^{18}$.

The questionnaire was adapted from validated 'sleep disturbance scale' developed in Rome and applied as survey questionnaire by sleep centre of Sydney Children's Hospital ${ }^{18,19}$. The questionnaire was translated into local language (Bangla) and tailored for appropriateness in the target group. In a self-administered questionnaire, parents were asked if their child had disturbed sleep at night excluding periods of illness. Apart from general information, questionnaire consisted of 20 items, one for each of the sleep disorders viz. Choking/gasping, abnormal leg movement, walking, frighten and forget, paralysis, bed wetting, irresistible sleep, breathing difficulty, panic attack and convulsions. The parents had to tick one of the alternatives that best fitted with their child's condition. The alternatives were: yes/ no/ not known. Parents were also asked if they had consulted a doctor in the last 12 months about their child's difficulty in sleeping. Academic performance was measured on the basis of cumulative results of term examinations in respective class throughout the year. Socioeconomy was considered on monthly family income and income of Tk. 10,000-20,000 was taken as middle class and the higher or lower figure were considered accordingly. Underlying medical conditions were included only when diagnosed by a medical specialist.

A test-retest reliability of the questionnaire was conducted at an interval of one week by distributing the questionnaire among a small group (30) of parents who have a school going child. Response to these questions was verified and questionnaire was revised to make it easily and uniformly comprehensible to the parents. Two investigators were recruited for the survey and they were also trained to explain the questions in a uniform manner to ensure quality and consistency of finding. A forwarding letter along with the questionnaire included a brief description of the study and written informed consent was obtained from each parent. The study was approved by the Ethical Review Committee of Khulna Medical College and Hospital.

Data from questionnaire and interview were cleaned and checked for validity. They were coded and entered in the Statistical Program for Social Science (SPSS version 12, SPSS Inc., Chicago) for analysis. For continuous variable mean, standard deviation and range were calculated. Chi-Square test was done for categorical variable to find out the significance. In all tests $p$ value below 0.05 was considered as significant. 


\section{Results}

A total of 1000 questionnaires were randomly distributed among the 6000 school children, half in the girls' school and the other half in boys' school. Initial return was around $55 \%$ but after first and second reminder, 353 (71\%) questionnaires were eventually returned from boys' school and 360 $(72 \%)$ from girls' school. Thus the total study population became $713(71.3 \%)$ between 5 to 16 years and the male: female ratio was 1:1.02. Sleep disorders (392) were noted in 202 (28.3\%) children with multiple problems. Boys and girls ratio of affected children was $1: 1.1$ and the mean (SD) age of the sufferer was 139 (32) months ranging from a minimum of 63 to a maximum of 198 months. Majority (43.1\%) of children belonged to middle class family and a small portion $(25.8 \%)$ came from low socioeconomy. Primary sleep disturbances $(235 ; 60 \%)$ were much more common than the secondary disturbances $(157 ; 40 \%)$ as shown in Table 1.

Table 1: Prevalence of sleep disturbance in school children $(n=713)$

\begin{tabular}{|c|c|c|c|}
\hline \multirow[t]{2}{*}{ Sleep Disorder (Subtotal) } & \multirow[t]{2}{*}{ Number of Problems } & \multicolumn{2}{|c|}{ Percentage } \\
\hline & & In 713 children & In 392 problems \\
\hline \multicolumn{4}{|l|}{ PRIMARY (235) } \\
\hline \multicolumn{4}{|l|}{ Dyssomnias (37) } \\
\hline Obstructive sleep apnoea & 26 & 3.6 & 6.6 \\
\hline Altitude insomnia & 07 & 1.0 & 1.8 \\
\hline Jet lag syndrome & 04 & 0.6 & 1.0 \\
\hline \multicolumn{4}{|l|}{ Parasomnias (187) } \\
\hline Restless leg syndrome & 13 & 1.8 & 3.3 \\
\hline Bruxism & 18 & 2.5 & 4.6 \\
\hline Sleep walking & 11 & 1.5 & 2.8 \\
\hline Sleep terror & 24 & 3.4 & 6.1 \\
\hline Nightmares & 53 & 7.4 & 13.5 \\
\hline Sleep paralysis & 04 & 0.6 & 1.0 \\
\hline Behavioural disorder & 12 & 1.7 & 3.1 \\
\hline Hallucination & 02 & 0.3 & 0.5 \\
\hline Sleep talking & 21 & 2.9 & 5.4 \\
\hline Nocturnal enuresis & 29 & 4.1 & 7.4 \\
\hline \multicolumn{4}{|l|}{ Hypersomnias (11) } \\
\hline Narcolepsy & 11 & 1.5 & 2.8 \\
\hline \multicolumn{4}{|l|}{ SECONDARY (157) } \\
\hline \multicolumn{4}{|l|}{ Medical conditions (22) } \\
\hline Gastro-oesophageal reflux disease & 02 & 0.3 & 0.5 \\
\hline Sleep asthma & 20 & 2.8 & 51 \\
\hline \multicolumn{4}{|l|}{ Mental condition (89) } \\
\hline Panic attack & 39 & 5.5 & 9.9 \\
\hline Post-traumatic stress disorder & 50 & 7.0 & 12.8 \\
\hline \multicolumn{4}{|l|}{ Neurological condition (46) } \\
\hline Epilepsy & 03 & 0.4 & 0.7 \\
\hline Headache & 43 & 6.0 & 11.0 \\
\hline Total & 392 & 55.0 & 100.0 \\
\hline
\end{tabular}


Among the primary disturbances parasomnias (187) were the highest followed by dyssomnias (37) and hypersomnias (11). Prominent disturbance under dyssomnia was obstructive sleep apnoea (3.6\%). Prominent disturbances under parasomnia were nightmares $(7.4 \%)$, nocturnal enuresis $(4.1 \%)$ and sleep terror (3.4\%). Secondary sleep disturbances were frequently associated with mental disease such as post traumatic stress disorder (7\%) and neurologic disease such as arousal headache $(6 \%)$ but medical diseases such as sleep asthma $(2.8 \%)$ were noticed in a small number of children.

School performances of the affected children were compared with that of normal children on the basis of term examination result (Table 2).

Table 2: School performance in relation to sleep status

\begin{tabular}{|c|c|c|c|c|c|}
\hline Sleep status & Total & \multicolumn{3}{|c|}{ School performance } & p value* \\
\hline & & Good No. (\%) & Average No. (\%) & Poor No. (\%) & \\
\hline Normal & 511 & $212(41.5)$ & $288(56.4)$ & $11(2.2)$ & \\
\hline Minor disorder & 29 & $10(34.5)$ & $08(27.6)$ & $11(37.9)$ & $<0.001$ \\
\hline Major disorder & 173 & $37(21.4)$ & $84(48.6)$ & $52(30.1)$ & \\
\hline Total & 713 & 259 & 380 & 74 & \\
\hline
\end{tabular}

* Compared between good and poor performances; Chi Square test

Given the average performance as a common feature, $41.5 \%$ of the normal children had good performance while $30.1 \%$ of symptomatic children had poor performance and the difference was highly significant $(\mathrm{p}<0.001)$. Percentage of poor performance in minor disorder group apparently seems to be higher $(37.9 \%)$ but when compared with major disorder group was found insignificant $(p=0.796)$. Even though the parents are concerned about sleep disturbances, the vast majority of them did not consult a physician for the problem unless there was associated medical, neurological or mental disease. Only $22(10.8 \%)$ parents consulted a physician for primary sleep disorder: nocturnal enuresis (15), sleep terror (4) and sleep walking (3).

Categories of sleep disturbances were divided into two different age groups: under-10 years (248) and over-10 years (465) of age (Table 3 ).

Table 3: Frequency of sleep disturbance according to age group

\begin{tabular}{|l|c|c|c|}
\hline \multicolumn{1}{|c|}{ Sleep Disorder } & $\begin{array}{c}\mathbf{6 0 - 1 2 0} \text { months }(\mathrm{n}=248) \\
\text { Problem (\%) }\end{array}$ & $\begin{array}{c}\mathbf{1 2 1 - 2 0 0} \text { months }(\mathrm{n}=465) \\
\text { Problem (\%) }\end{array}$ & v value* $^{*}$ \\
\hline Primary & $11(2.8)$ & $26(6.7)$ & 0.207 \\
Dyssomnias & $59(15.1)$ & $128(32.7)$ & 0.107 \\
Parasomnias & $01(0.3)$ & $10(2.6)$ & 0.061 \\
Hypersomnias & $05(1.2)$ & $17(4.3)$ & 0.376 \\
\hline Secondary to & $22(5.6)$ & $67(17.1)$ & 0.015 \\
Medical condition & $11(2.8)$ & $35(8.9)$ & 0.076 \\
Mental condition & $109(27.8)$ & $283(72.2)$ & \\
Neurological condition & \multicolumn{1}{c|}{ Total } & & \\
\hline
\end{tabular}

\section{* Chi Square test}

One hundred and ninety children had more than one disturbance. Sixty four (25.8\%) under-10 children had 109 problems and 138 (29.7\%) over10 children had 283 problems which denote the problem ratio per affected children $(1.7: 2.1)$ is higher in older children but this was not statistically significant. In the other way round, all the sleep categories were higher in frequency in older children than young children but none of the differences were statistically significant except the problem with mental diseases $(\mathrm{p}=0.015)$. Regarding gender difference, 94 (26.6\%) male children had 168 problems and $108(30 \%)$ female children had 224 problems which underscores higher problem ratio per affected children (1.8: 2.1) in females but this was not statistically significant (Table 4). 
Table 4: Gender difference in sleep disturbance

\begin{tabular}{|l|c|c|c|}
\hline \multicolumn{1}{|c|}{ Sleep Disorder } & $\begin{array}{c}\text { Male }(\mathrm{n}=353) \\
\text { Problem (\%) }\end{array}$ & $\begin{array}{c}\text { Female }(\mathrm{n}=360) \\
\text { Problem (\%) }\end{array}$ & p value* \\
\hline Primary & $26(6.6)$ & $11(2.8)$ & 0.018 \\
Dyssomnias & $80(20.4)$ & $107(27.3)$ & $<0.001$ \\
Parasomnias & $01(0.3)$ & $10(2.6)$ & 0.006 \\
Hypersomnias & $17(4.3)$ & $05(1.2)$ & 0.024 \\
\hline Secondary to & $30(7.7)$ & $59(15.1)$ & 0.006 \\
Medical condition & $14(3.6)$ & $32(8.2)$ & 0.012 \\
Mental condition & $168(42.9)$ & $224(57.1)$ & \\
Neurological condition & & & \\
\hline \multicolumn{1}{c}{ Total } & & & \\
\hline
\end{tabular}

* Chi Square test

On the other hand, most of the sleep categories, when compared individually, were significantly higher in female children than male, particularly parasomnia $(\mathrm{p}<0.001)$ but dyssomnias and problems secondary to medical diseases were higher in male children.

\section{Discussion}

Sleep disturbances in the present study were noted in $28.3 \%$ children with overlapping problems (1.9 problems per child). Frequently encountered primary disorders were nightmares (7.4\%), nocturnal enuresis $(4.1 \%)$, obstructive sleep apnoea syndrome (3.6\%) and sleep terror $(3.4 \%)$. In Great Britain, sleep problems of varied nature and intensity affect $20 \%$ children at 5 years, $6 \%$ at 11 and less than $1 \%$ children had serious problems from age 9 onwards $^{16}$. The decline in sleep problems with age provides indirect evidence that these problems have a good prognosis but several researchers reported that sleep problems persist in a subgroup of children ${ }^{11,16}$. Studies in Belgium, Sweden, New Zealand and Spain have reported current sleep problems between $33 \%$ to $46 \%$, well above the prevalence study in Britain, although part of the discrepancy may be due to use of different questions to ascertain sleep problems ${ }^{12,13,20}$.

The overall prevalence of sleep disorder in Beijing was $21.2 \%$ and was similar to that in western countries $(20-25 \%)^{1}$. It included parasomnia symptoms [bruxism (6.5\%), sleep talking (4.9\%), enuresis $(1 \%)$, sleep walking $(2.5 \%)$, restless sleep $(5 \%)$ and leg movement $(1.9 \%)$ ] and problem of sleep disordered breathing [frequent snoring $(5.6 \%)$, mouth breathing $(4.1 \%)$, choking/gasping $(0.9 \%)$ and breathing pauses $(0.2 \%)]^{1}$. Johnson and colleagues reported that prevalence rate of obstructive sleep apnoea syndrome in children under 8 years of age was approximately $2.5 \%$ and as high as $6.5 \%$ in adolescents ${ }^{21,22}$. Kotagal and Pianosi noticed restless leg syndrome in $6 \%$ children and $80 \%$ of them had periodic limb movement disorder ${ }^{23}$. Overall prevalence of sleep disturbance in our study is slightly higher than that in China and Britain but isolated disorders like nightmares and nocturnal enuresis were much higher and obstructive sleep apnoea syndrome and restless leg syndrome were lower in frequency.

This study revealed that poor school performance is much higher in affected children than normal children $(7.3 \%$ vs. $1.5 \%$; $<<0.001)$. However, only $10.8 \%$ parents of sleep disordered children consulted doctors for the disturbances. Blunden and colleagues observed that parents of children attending the clinic raised sleep problems only in $13.9 \%$ of cases during consultation and despite relative high percentage $(24.6 \%)$ of sleep disturbances in childhood only $11.4 \%$ sought medical advice ${ }^{15}$. Excessive daytime sleepiness, which is related to obstructive sleep apnoea syndrome and delayed sleep phase syndrome, is the most overlooked category of sleep disturbance because it is easily mistaken for laziness, disinterest or depression in children who ultimately get lower grades than peers in class ${ }^{4,24}$. In Britain, parents of severe cases of sleep disorder are reluctant to ask for medical help because they think health service cannot help in this area ${ }^{16}$. Similarly, our study parents were also concerned about sleep disorders in children but they did not consider it as a medical problem to share with the physicians. However, treatment of sleep disturbance in school children might help in improvement of school performances. 
In this study, proportion of over-10 year sufferers $(29.7 \%)$ was higher than under-10 (25.8\%) and proportion of affected children among girls (30\%) was more than the boys $(26.6 \%)$ but none of the differences were statistically significant. However, considering the number of problems, most (4/6) of sleep categories were significantly higher in girls. In fact, prevalence of sleep disorder in children is related to age and stage of physical development ${ }^{25,26}$. In China, boys had more sleep disorders than girls $(22.4 \%$ vs. $19.8 \%$; $=0.013)$ and the prevalence of bruxism was significantly higher in preschool (8.5\%) than school (3.7\%) children ${ }^{1}$. In Australia, sleep disorder persisted across the whole range (4-16 years) showing only small age related decrease and apart from sleep related hyperhydrosis, no strong gender difference was found ${ }^{15,27}$. Our observation regarding age was nearly similar, but regarding gender, parasomnia was remarkably higher in girls, which might be related to insecurity in our society.

The principal limitation of the present study was the identification of sleep disturbances on questionnaires and direct interview without polysomnography due to lack of facilities. Other limitations were a sample of convenience, reliance on parental recall report and their limited awareness of the potential consequences of the sleep problem on the children and families. Several confounding factors influence the school performance besides sleep disorder, which was beyond the scope of present paper.

\section{Conclusions}

- In the 2 selected schools in Khulna city of Bangladesh $28.3 \%$ had sleep problems.

- Sleep disorders had a significant negative impact on school performance.

Further large scale studies can be done to evaluate the national picture. There is also a need for increased awareness of sleep problems in the community which should be properly addressed at consultation due to its impact on children and families.

\section{Acknowledgements}

We are grateful to all the teachers of Coronation Girls School, particularly the Head Master (Mrs Farhana Naz) and the teachers of Khulna Zilla School, particularly the Head Master (Mrs Maleka Begum) for their encouragement of parents and immense cooperation in carrying out this study. We are thankful to Dr Urmi Chowdhury and Dr Sajjad Al Hossain for their tireless effort in data collection in the school and the sleep clinic as well.

\section{References}

1. Liu X, Ma Y, Wang Y, Jiang Q, Rao X, Lu X. An epidemiological survey of the prevalence of sleep disorder among children 2 to 12 years old in Beijing, China. Pediatrics 2005; 115: 266-8.

http://dx.doi.org/10.1542/peds.2004-0815I

2. Smedje H, Broman JE, Hetta J. Parents' report of disturbed sleep in 5-7 years old Swedish children. Acta Pediatrica 1999; 88: 858-65. http://dx.doi.org/10.1080/08035259950168793

3. Kotagal S, Pianosi P. Sleep disorders in children and adolescents. British Medical Journal 2006; 332: 828-32. http://dx.doi.org/10.1136/bmj.332.7545.828

4. Stores G. Children's sleep disorder: Modern approaches, developmental effects and children at special risk. Developmental Medicine and Child Neurology 1999; 41: 56873. http://dx.doi.org/10.1017/S001216229900119 $\underline{X}$

5. Owens JA. Sleep Medicine. In: Kleigman RM, Behrman RE, Jenson HB, Stanton BF, editors. Nelson Textbook of Pediatrics. 14th edition. Philadelphia: Saunders; 2008: 91-9.

6. Kerr S, Joett S. Sleep problem in preschool children: a review of literature. Child: Care Health and Development 1994; 20: 379-91. http://dx.doi.org/10.1111/j.13652214.1994.tb0 0400.x

7. Quine L. Sleep problems in primary school children: comparison between mainstream and special school children. Child: Care Health and Development 2001; 27: 201-20. http://dx.doi.org/10.1046/j.13652214.2001.002 $\underline{13 . \mathrm{X}}$

8. Chervin RD, Archbold KH, Panahi P. Sleep problems seldom addressed at two general paediatric clinics. Pediatrics 2001; 108: 114954.

9. Luginbuehl M, Kathy L, Klug B, Ferron J, Anderson WM, Benbadis SR. Paediatric sleep disorders-validation of sleep disorder inventory for students. School Psychology Review 2008; 37: 409-31.

10. Sadeh A, Raviv A, Gruber BL. Sleep pattern and sleep disruption in school age children. Developmental Psychology 2000; 36; 291-301. http://dx.doi.org/10.1037/0012-1649.36.3.291 
11. Pollock JI. Night waking at 5 years of age. Journal of Child Psychology \& Psychiatry 1994; 34: 699-708.

http://dx.doi.org/10.1111/j.14697610.1994.tb0 $\underline{1215 . x}$

12. Mindell JA. Sleep disorders in childhood. Health Psychology 1993; 12: 151-62. http://dx.doi.org/10.1037/0278-6133.12.2.151

13. Adair RH, Bauchner H. Sleep problems in childhood. Current Problems in Pediatrics 1993; 23: 147-70. http://dx.doi.org/10.1016/00459380(93)90011$\underline{Z}$

14. American Academy of Sleep Medicine. International Classification of Sleep Disorders. Diagnostic and coding manual. West chester, Illinois. Am Acad Sleep Med 2001

15. Blunden S, Lushington $\mathrm{K}$, Lorenzen $\mathrm{B}$, Ooi $\mathrm{T}$, Fung F, Kennedy D. Are sleep problems under recognized in general practice. Archives of Disease in Childhood 2004; 89: 708-12. http://dx.doi.org/10.1136/adc.2003.027011

16. Rona RR, Li L, Gulliford MC, Chinn S Disturbed sleep - effect of socio-cultural factors and illness. Archives of Disease in Childhood 1998; 78; 20-5

http://dx.doi.org/10.1136/adc.78.1.20

17. Guilleminault C, Biol D, Palambini L, Pelayo R, Chervin RD. Sleep walking and sleep terror in pre-pubertal children. Pediatrics 2003; 111: e17-24.

http://dx.doi.org/10.1542/peds.111.1.e17

18. Bruni O, Ottaviano S, Guidetti V, Romeli M, Innocenzi $\mathrm{M}$, Cortesi $\mathrm{F}$ et al. The sleep disturbance scale for children: construction and validation of an instrument to evaluate sleep disturbance in childhood and adolescence. Journal of Sleep Research 1996; 5: 251-61. http://dx.doi.org/10.1111/j.13652869.1996.002 $\underline{51 . x}$

19. Campbell TA, Papadoupolus DJ, Verge CF, Williamson BD, Teng A. Incidence of sleep disorder in children with presumed normal variant short stature. Journal of Paediatrics and Child Health 2005; 41: 358-60. http://dx.doi.org/10.1111/j.14401754.2005.006 $\underline{31 . x}$

20. Khan A, Merckt C, Rebuffat E. Sleep problem in healthy preadolescents. Pediatrics 1989: 84: 542-6.

21. Johnson EO, Roth T. An epidemiological study of sleep disordered breathing symptoms in adolescents. Sleep 2006; 29: 1135-42.

22. Marcus CL, Keens T, Bautista DB, Von Pechann WS, Davidson SL. Obstructive sleep apnoea in children with Down's syndrome. Pediatrics 1991; 88: 132-9.

23. Kotagal S, Silber MH. Childhood onset restless leg syndrome. Annals of Neurology 2004; 56: 803-7. http://dx.doi.org/10.1002/ana.20292

24. Wolfson AR, Karskadon MA. Understanding adolescent sleep patterns and school performances-a critical appraisal. Sleep Medicine Reviews 2003; 7: 491-506. http://dx.doi.org/10.1016/S10870792(03)9000 $\underline{3-7}$

25. Mindell JA, Owens JA, Carskadon MA. Developmental factors of sleep. Child and Adolescent Psychiatric Clinics of North America 1999; 8: 695-725.

26. Morrison DN, McGee R, Stanton WR. Sleep problem in adolescence. Journal of the American Academy of Child and Adolescent Psychiatry 1992; 31: 94-9 http://dx.doi.org/10.1097/00004583199201000 $\underline{-00014}$

27. Ohayon MM, Roberts RE, Zulley J, Smirne S, Priest RG. Prevalence and pattern of problematic sleep among older adolescents. Journal of the American Academy of Child and Adolescent Psychiatry 2000; 39: 1549-56 http://dx.doi.org/10.1097/00004583200012000 $\underline{-00019}$ 